\title{
EVALUATING THE USE AND COMMUNICATION OF SEISMIC HAZARD MAPS: A CASE STUDY OF METRO VANCOUVER, BRITISH COLUMBIA, CANADA
}

\author{
MEREDITH FYFE \& SHERI MOLNAR \\ Department of Earth Sciences, The University of Western Ontario, Canada
}

\begin{abstract}
The Metro Vancouver region of southwestern British Columbia, Canada, is exposed to significant earthquake risk. Earthquake hazard has yet to be mapped to an effective scale in Metro Vancouver and so it is critical to generate comprehensive seismic hazard maps for the region. The Metro Vancouver Seismic Microzonation Project is tasked with the assessment and mapping of earthquake shaking hazard and liquefaction and landslide susceptibility hazards at a 1:25,000 scale. The detailed hazard information and data collected as part of this project, like most traditional hazard studies, is highly technical and unsuitable for the needs of intermediate users (e.g. regional planners and emergency managers). In this study we evaluate metrics and delivery format used to communicate seismic hazard information to intermediate users so it may be applied effectively in regional planning and emergency management strategies. Our methodology to evaluate effective communication of the seismic hazard products (GIS shapefiles and maps) involves a stakeholder workshop and online questionnaire survey. Existing microzonation maps for other regions in Canada are referenced throughout this consultation process and feedback is used as a benchmark to develop upon. A sequence of iterative discussion and consultation is necessary to determine the comprehensible metrics, desired interaction level and stylistic preferences to be used in final mapped products. Responses reiterate that the use of technical metrics is not effective in communicating hazard to intermediate users; separate map products are required for primary and intermediate users. Additionally, participants express importance of visual simplicity, open access to background data and interactive capabilities (e.g. GIS shapefiles). Feedback indicates that a lack of standardization leads to misinterpretation when comparing seismic microzonation maps of different regions; thus, results of this consultation process are integrated into a set of preliminary recommendations for producing seismic microzonation maps in a move towards standardization.

Keywords: seismic microzonation, seismic hazard, earthquake, hazard communication, iterative consultation, stakeholder engagement, Cascadia, Metro Vancouver, British Columbia, Canada.
\end{abstract}

\section{INTRODUCTION}

Maps are an effective means of delivering extensive and complex information related to natural hazards in a compact product [1], [2]. They are the preferred method of communicating seismic hazard to a variety of audiences. It is imperative that decision-makers have access to comprehensive information regarding society's exposure to seismic hazards, particularly engineers for the purpose of seismic design and retrofitting, but also land-use planners and emergency managers for risk mitigation and response planning [1]-[3]. Seismic hazard maps are typically produced for the needs of primary users (e.g. specialized engineers and seismologists) and depict hazard using technical metrics; however, the same hazard maps may be referenced by intermediate users (e.g. land use planners and emergency managers) in the absence of map products presenting seismic hazard with more intuitive metrics. Additionally, these technical map products are often made available to the public with limited supplementary information, further impairing their effectiveness. Seismic hazard maps often fail to adequately communicate hazard to intermediate users who, without fundamental understanding of seismic hazard, misinterpret the maps. For example, Marti et al. [2] evaluated seismic hazard communication through maps in Switzerland and concluded that, 
even while following best practice recommendations, many users, particularly non-technical public audiences, had difficulty understanding updated seismic hazard map products. There exists a significant knowledge gap between primary and intermediate users, suggesting that communicating seismic hazard to all stakeholders with a single map tool is inappropriate and ineffective in conveying the intended information [1].

Metro Vancouver is a densely populated region with significant critical infrastructure. The region is exposed to seismic hazards due to its proximity to an active subduction zone with a history of destructive earthquakes [4]. The Auditor General of British Columbia concluded in a 2014 report that "Emergency Management British Columbia (EMBC) cannot demonstrate that it is adequately prepared to manage the effects of a catastrophic earthquake" [5]. Much of the damage from seismic events in Metro Vancouver will result from the physical ground shaking or permanent ground failures resulting from shaking (landslides and liquefaction), which is altered by variations in subsurface soils. A detailed understanding of subsurface ground conditions and their spatial variability across a region - seismic microzonation - is required to mitigate damage/losses to buildings, infrastructure and life as a result of these earthquake shaking hazards [6]. Seismic microzonation is a valuable tool for identifying areas with increased seismic hazard within this region. Knowledge of the potential amplification of seismic energy in the subsurface is applied in construction and retrofitting of the built environment to better withstand earthquake shaking effects [3], [4], [6]. Information about likely shaking effects is also applied to land-use planning, emergency management and insurance [1], [2], [6]. However, existing studies of Metro Vancouver's subsurface conditions that affect ground motion are outdated and/or lack sufficient detail [7].

For these reasons, the Metro Vancouver Seismic Microzonation Project (MVSMP) [8], supported by EMBC, has the primary objective of updating the current knowledge of the region's subsurface geological and geophysical characteristics (earthquake site effects) to estimate potential ground motion considering the seismic sources. This information, in the form of map products, will be provided to a diverse group of stakeholders/decision-makers in Metro Vancouver for engineering, seismic design and retrofitting, building code amendment, land-use planning, and disaster preparation. The MVSMP is tasked with the assessment and mapping of earthquake shaking, liquefaction susceptibility and landslide/slope instability hazards [9], all of which utilize technical metrics to describe ground motion. This case study focuses primarily on effective communication of earthquake shaking hazard for intermediate users without fundamental understanding of technical metrics; however, mapping format recommendations will be applied to all earthquake hazard mappings of the MVSMP. In this case study, perspectives on mapping parameters are gathered through a stakeholder workshop and online questionnaire survey. Further iterative consultation with stakeholders, consistent with the concluding recommendations of Marti et al. [2], will be accomplished to determine final mapping specifications.

This paper outlines the MVSMP and regional seismicity as relevant background, then presents preliminary workshop and survey outcomes of stakeholder perspectives and preferences for future seismic hazard map products. We conclude with recommendations to facilitate communication of seismic hazard to intermediate users in Metro Vancouver derived from consultative review of preliminary seismic microzonation map products.

\section{SEISMIC HAZARD POTENTIAL OF METRO VANCOUVER}

The Metro Vancouver region of southwestern British Columbia is adjacent to the northern end of the Cascadia subduction zone, which runs parallel to the west coast of continental North America [7], [10]. The oceanic Juan de Fuca tectonic plate is actively subducting below the North American plate at an average rate of $2-4 \mathrm{~cm} /$ year. This active tectonic setting leads 
to a variety of earthquake sources: shallow crustal North America plate events, inslab events (up to $70 \mathrm{~km}$ depth) in the subducting Juan de Fuca plate, and megathrust earthquakes along the subduction interface [3], [4]. Significant Cascadia subduction zone earthquakes with potential moment magnitudes (M) of up to 9.0, i.e., megathrust earthquakes, are hugely destructive, though infrequent with estimated recurrence intervals of approximately 500 years [4], [7], [10], [11]. Inslab earthquakes are the most frequent earthquake source type in the region and produce high intensity shaking at short periods (e.g. Jackson et al. [12]). However, damage from inslab earthquakes has been relatively minimal in British Columbia [4] as they occur relatively deep, producing lower intensities than crustal events of the same magnitude, and the largest magnitude events tend to occur away from Metro Vancouver. Vancouverites are generally aware of the threat of earthquakes in the region, including the potential of a megathrust event. The Government of British Columbia has spent over $\$ 1.8$ billion in the seismic retrofitting of public schools for over a decade [13] and has published resources related to earthquake preparedness [14]. Local municipal governments are also tackling the issue in their own ways. For example, the City of Vancouver has invested in assessing the seismic mitigation of their high-risk buildings [13]. It is well understood that earthquakes cannot be stopped, their explosive energy cannot be lessened, and their occurrence cannot be predicted with reliable accuracy in a timely manner; all that can be done is to prepare for their effects [1], [4].

\subsection{Seismic microzonation}

Seismic microzonation is a means of subdividing a region into zones based on similar potential earthquake effects; it is a component of urban or regional scale seismic hazard mapping [6]. Seismic microzonation maps display predicted variation in earthquake shaking due to local site conditions (i.e. site effects, basin edges, topographic effects), and consider secondary shaking hazards (landslides and liquefaction). This mapping technique requires subsurface geological, geophysical and geotechnical information described by technical siteclassification metrics [6]. This information is obtained from remote sensing datasets (e.g. topography from LiDAR), invasive measurements (e.g. boreholes) and non-invasive measurements (e.g. seismic surveys, surface wave analysis) [6].

\subsection{Site effects}

Earthquake source (e.g. magnitude) and path (e.g. geometric attenuation) effects significantly affect ground motion experienced at the surface. However, the strength of ground shaking at any particular location is related primarily to the local site conditions (site effects) [6]. Source and path effects are generally well determined from recording earthquakes worldwide for over 100 years. However, site effects are poorly constrained as a result of large-scale heterogeneity of the subsurface and only recent scientific investigation in the last few decades. Earthquake site characterization, understanding how the subsurface ground conditions will alter earthquake shaking, is currently the most crucial component of accurate seismic hazard prediction. Thus, detailed understanding of site effects is critical to estimate potential damage and losses to the built and human environment resulting from earthquakes.

The amplification of earthquake energy as it approaches the surface is related largely to the material properties (density, velocity) and thickness of sediments overlying bedrock [3], [6]. The strength of the resulting shaking varies considerably across a region as sediment and bedrock characteristics vary spatially. The amplification of shear waves and resulting strength of earthquake-induced shaking is generally greater at sites underlain by soft soil than 
at sites underlain by bedrock, and often greater at sites underlain by thick, unconsolidated sediments or within bedrock basins [3], [15]-[17]. Quantification of site effects is a critical outcome in developing earthquake mitigation or adaptation strategies.

\subsection{Site effect metrics}

The US National Earthquake Hazards Reduction Program (NEHRP) categorizes typical soil profiles into site classes corresponding to values of technical site-characterization metrics, chiefly the time-averaged shear-wave velocity to a depth of 30 metres, $\mathrm{V}_{\mathrm{S} 30}$ [18]. The National Building Code of Canada (NBCC) adopted the NEHRP site-classification system in 2005 (with modified amplification factors for each class), utilizing $\mathrm{V}_{\mathrm{S} 30}$ as the standard metric for describing ground conditions [3], [15], [19] (Table 1). Hence, most Canadian seismic microzonation maps depict soil hazard using $\mathrm{V}_{\mathrm{S} 30}$ or its associated NBCC site class [3], [16], [20]-[23]. The $\mathrm{V}_{\mathrm{S} 30}$-based site classification system is the generally accepted method of defining the hazard potential of earthquake shaking/amplification [3], [4], [24].

Table 1: NBCC site classes corresponding to $\mathrm{V}_{\mathrm{S} 30}$ for soil types [19].

\begin{tabular}{|clc|}
\hline Site class & Type of soil profile & $\mathrm{V}_{\mathrm{S} 30}(\mathrm{~m} / \mathrm{s})$ \\
\hline A & Hard rock & $\mathrm{V}_{\mathrm{S} 30}>1500$ \\
B & Rock & $760<\mathrm{V}_{\mathrm{S} 30}<1500$ \\
C & Very dense soil and soft rock & $360<\mathrm{V}_{\mathrm{S} 30}<760$ \\
D & Stiff soil & $180<\mathrm{V}_{\mathrm{S} 30}<360$ \\
E & Soft soil & $\mathrm{V}_{\mathrm{S} 30}>180$ \\
F & Liquefiable soils and sensitive, organic and highly & Site specific \\
& plastic clays & evaluation required \\
\hline
\end{tabular}

Amplification of ground motion is affected by the fundamental site period $\left(\mathrm{T}_{\mathrm{S}}\right)$ or the inverse, the resonance frequency, of a site [25]. Highest amplification occurs at a particular resonance frequency - the fundamental peak frequency $\left(f_{0}\right)$ - related to the thickness $(\mathrm{h})$ and average shear-wave velocity $\left(\mathrm{V}_{\text {Savg }}\right)$ of a soil layer (see eqn (1))

$$
f_{0}=\frac{V_{S_{\text {avg }}}}{4 h} \text {. }
$$

Higher $f_{0}$ values correspond to sites with a thin and/or stiff sediment layer overlying bedrock; lower $f_{0}$ correspond to thick and/or soft sediment overlying bedrock. Engineers readily understand $\mathrm{T}_{\mathrm{S}}$ (and to a lesser degree, $f_{0}$ ) as it affects ground motion amplification, and so $\mathrm{T}_{\mathrm{S}}$ or $f_{0}$ maps can be generated and used for engineering or planning purposes [26].

\subsection{The Metro Vancouver seismic microzonation project}

EMBC recognizes that the existing soil hazard map for the Lower Mainland of British Columbia [3] lacks the necessary detail for its current applications in seismic risk assessment and emergency response preparedness. This soil hazard map is based on surficial geology maps produced by the Geological Survey of Canada (GSC) and is locally modified where more detailed borehole data and geological investigations have been conducted [3]. A Vs model for southern British Columbia was developed from compilation of Vs measurements [27] and used to assign relative amplification hazard to the mapped surficial geology units. As a result of potential local variation of soil properties within the same geological unit and limited subsurface investigations, the mapping is approximate and too coarse for the needs 
of current and future seismic hazard assessment. The NBCC [3], [15], [16] and British Columbia School Seismic Mitigation Program [3] base their estimations and decisionmaking on the 2005 soil hazard map of Metro Vancouver. The limited detail of this map affects the accuracy of seismic hazard assessment and, further, risk assessment. Ultimately, improved seismic microzonation mapping would provide decision-makers with the necessary detailed and accurate information to mitigate risk and losses from future earthquake events.

A comprehensive geodatabase with adequate spatial coverage to achieve mapping of ground shaking, mass movements and soil liquefaction hazards at a 1:25,000 scale is under development [9]. The geodatabase is assembled from a compilation of available and private geological, geophysical and geotechnical data sources, and supplemented with non-invasive seismic testing. The site characterization metrics used to quantify this geological, geophysical and geotechnical information are comprehensible to primary users. These technical siteclassification metrics are too complex for intermediate users; this presents the challenge of ensuring correct interpretation of seismic microzonation maps by intermediate users [1], [2].

\section{USER CONSULTATION AND RESULTS}

Following the concluding recommendation in Marti et al. [2], we consulted with anticipated end-users of seismic hazard products in the Metro Vancouver region and across Canada through a stakeholder workshop (December 2019) and an online survey questionnaire (ongoing). The objective of consultation is to facilitate communication, and to establish endusers' hazard awareness, stylistic and metric preferences, and anticipated uses of the map products. Feedback is used to evaluate the use and communication of existing and draft seismic microzonation maps of Canadian regional centres. This user engagement is the initial step in the iterative consultation process; recommendations will be applied to future products of the MVSMP and integrated into a set of guidelines for producing seismic microzonation maps in Canada in a move towards standardization.

\subsection{Stakeholder engagement workshop}

A group of 36 stakeholders attended an engagement workshop in Vancouver. Participants represented local municipalities, industry, the GSC, EMBC, practicing structural and geotechnical engineers, consultants, and other regional and provincial organizations. This diverse group of participants was comprised of professionals self-identifying as: engineers (15), emergency managers (7), planners (4), research scientists (6), and "other" (4) predominantly comprising GIS technicians. A brief project summary, seismic microzonation theory and data inputs necessary for high quality seismic microzonation were presented.

Participants were separated into five groups with mixed professional representation in each to foster discussion and peer-learning. The groups first coloured a blank map of Metro Vancouver, indicating areas susceptible to landslides or liquefaction, to assess engaged stakeholders' awareness of the spatial distribution of secondary earthquake shaking hazards. Each group then completed four map-based exercises, contrasting and comparing two example seismic hazard maps per exercise (Fig. 1): (1) landslide hazard vs. liquefaction susceptibility; (2) liquefaction susceptibility vs. liquefaction potential [28]; (3) site characterization metrics $-f_{0}$ vs. $\mathrm{T}_{\mathrm{S}}$; and (4) site characterization metrics $-f_{0}$ vs. $\mathrm{V}_{\mathrm{S} 30}$. Groups completed written responses to questions related to each map pair, and then the dialogue was opened to the room to share answers and provide feedback on the draft map products. Discussion and feedback related to the map comparisons can be organized into four themes: (1) metric comprehension; (2) data categorization and visualization; (3) data/map interaction capability; and (4) data access. 


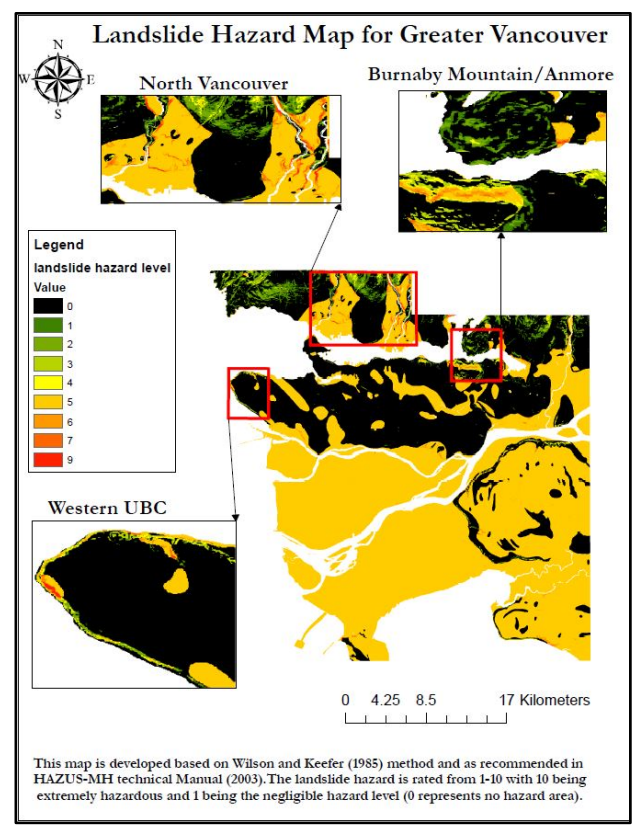

(a)

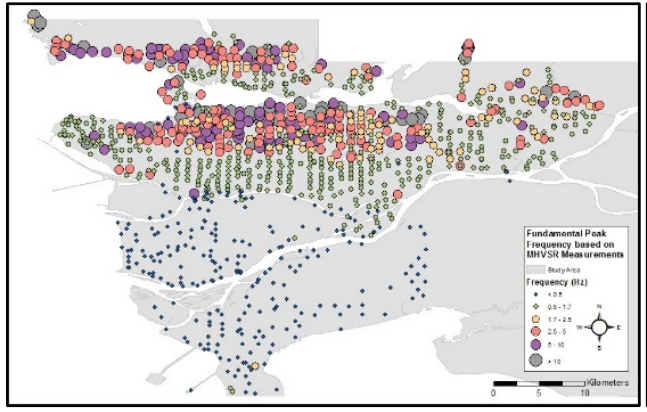

(d)

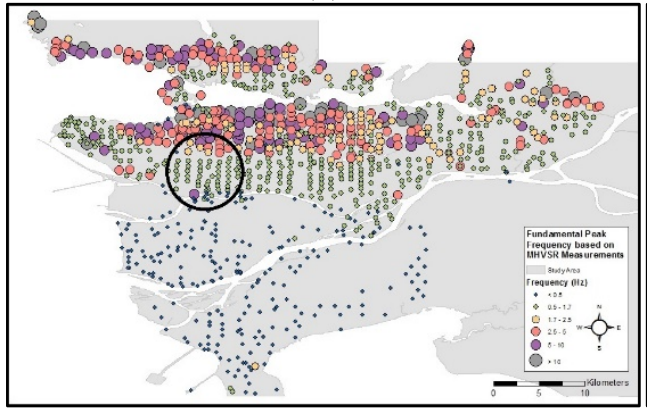

(f)

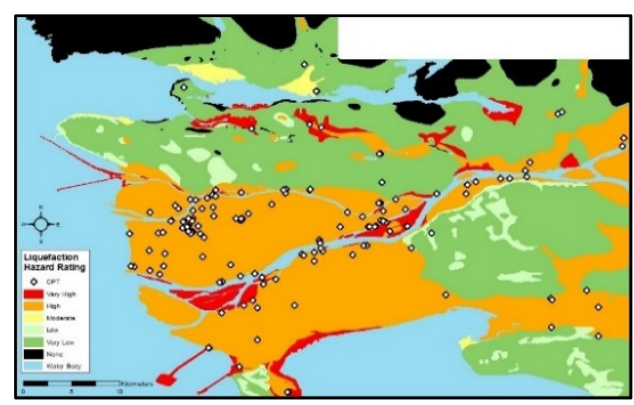

(b)

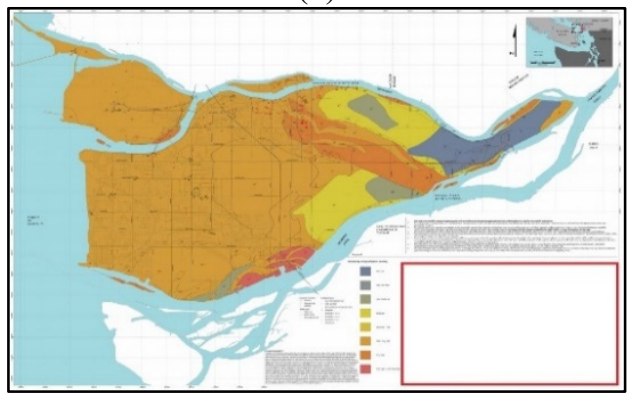

(c)

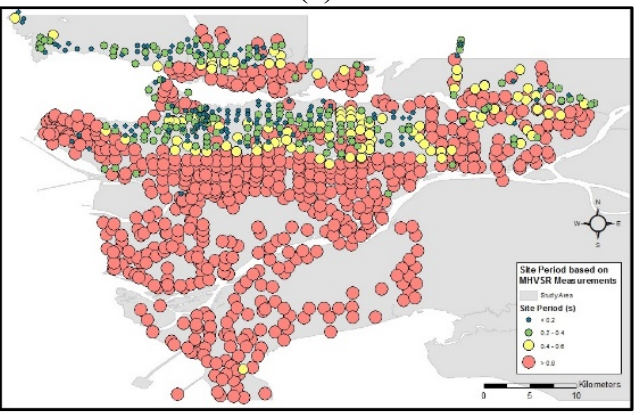

(e)

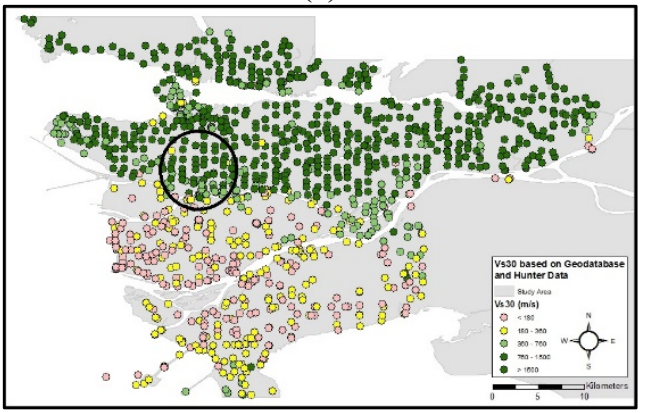

$(\mathrm{g})$

Figure 1: Maps presented for the workshop exercises. Exercise 1 compares (a) landslide hazard and (b) liquefaction susceptibility. Exercise 2 compares (b) and (c) liquefaction potential [28]. Exercise 3 compares (d) $\mathrm{f}_{0}$ and (e) $\mathrm{T}_{\mathrm{s}}$. Exercise 4 compares (f) $f_{0}$ and $(g) V_{\mathrm{S} 30}$, for the circled region. 
The metrics typically employed to express local site conditions and landslide and liquefaction potential (e.g. $\mathrm{V}_{\mathrm{S} 30}, f_{0}, \mathrm{~T}_{\mathrm{S}}$, surficial geology, amplification at selected periods, ground displacement, depth to bedrock) are suited to participants self-identified as primary users. However, primary-user participants expressed that each of these metrics are not universally or independently useful, and must be used in combination for decision-making purposes. Primary users acknowledged that the $\mathrm{V}_{\mathrm{S} 30}$ metric is integrated into seismic design of buildings and bridges in Canada (e.g., NBCC) and required for risk modelling applications, but should not be the only metric for which maps are produced. Intermediate user-type participants expressed that these metrics are not intuitive and are inappropriate for public audiences; maps (d)-(g) of Fig. 1 were not readily understood by these users. Intermediate users reported that they must currently hire external consultants to translate reports/maps communicating seismic hazard with these technical metrics.

Participants expressed that data represented by symbols (points), e.g. Fig. 1(d)-(g), are not as intuitive as data represented by colour contours. Additionally, data grouped into more than seven classes are indistinguishable. Colours elicit emotional responses which, though beneficial, may be misinterpreted. The use of the colours black or green in mapped products was determined to be misleading, e.g. Fig. 1(a) and (b). Green is often interpreted to be "good" or "safe", and black may be interpreted to mean "no risk", "no data" or a different hazard entirely. Use of bright red may be too alarming for public map products.

An interactive map product offering flexibility was requested by primary and intermediate users. Ability to view data and metadata, and toggle between metrics, is necessary when used for reference. Scenario-earthquake-based map products, considering hazard at specified periods of earthquake shaking, was requested by intermediate users.

Participants recognize that background data are not typically made publicly available for proprietary and/or privacy reasons. However, the dataset of geological and geotechnical information compiled for this study is important for public safety and to improve societal resilience to earthquakes. Participants agree that original data should be made accessible to relevant users, especially for detailed inspection prior to site-specific investigation, and to examine data density and irregularities.

\subsection{Online questionnaire survey}

We developed an online survey regarding seismic microzonation mapping and related earthquake hazard metrics using examples of existing Canadian seismic microzonation maps [3], [16], [20]-[23]. The purpose of the survey is to analyze seismic hazard metric comprehension, and metric and formatting preferences. We also seek to understand if and how existing seismic microzonation maps are used in Canada to improve future MVSMP map products from the survey's feedback.

The online survey was developed at Western University and went through ethics review. The survey is a series of 54 questions hosted on the Qualtrics platform [29]. The first set of questions gather respondent profiles and interaction with seismic hazard; further questions evaluate familiarity with seismic microzonation and use of Canadian seismic microzonation products, readability and interpretation of existing seismic microzonation maps, and siteclassification metric preferences. Participants identify their user type (creator or user of maps) and their profession. The survey involves self-evaluation to determine users' level of expertise related to their peers and other user types. The survey, offered in English and French, was delivered to participants of the stakeholder engagement workshop in Vancouver, and to participants of a multi-hazard risk and resilience workshop and a Global Earthquake Model OpenQuake workshop, both held in November 2019 at Western University. The 
online survey URL was also communicated to known seismic microzonation map creators and users belonging to an array of organizations across Canada via personal communication.

Preliminary outcomes of survey questions analyzed in this study (Table 2) are presented, noting the online survey is ongoing (not closed). A total of 47 useful responses have been received: 23 participants self-identified as "creators" and 24 as "end-users" of seismic hazard maps. The creators are hazard researchers/consultants/engineers that actively produce seismic hazard maps. End-users (e.g. planners, emergency managers, consultants, engineers, students) were further divided into "technical" (six respondents) and "non-technical" (18 respondents) to evaluate and compare responses from primary (technical) and intermediate (non-technical) user types.

Table 2: Online survey questions reviewed in this study.

\begin{tabular}{|c|c|}
\hline Question & Possible response \\
\hline $\begin{array}{l}\text { Please identify whether you are more of a } \\
\text { creator of seismic hazard maps or an end } \\
\text { user. }\end{array}$ & Creator; End user \\
\hline $\begin{array}{l}\text { Please identify your profession/ } \\
\text { interaction with seismic hazard mapping. }\end{array}$ & $\begin{array}{l}\text { Hazard researcher/Consultant/Engineer } \\
\text { (creator); Engineer (end user); Emergency } \\
\text { manager (end user); Regional planner (end } \\
\text { user); Hazard or risk analyst/Consultant (end } \\
\text { user); Student (trainee); Other }\end{array}$ \\
\hline How would you rate your seismic hazard & Minimal knowledge (0) to Highly \\
\hline knowledge? & knowledgeable (10) \\
\hline $\begin{array}{l}\text { How would you rate your level of } \\
\text { expertise with seismic hazard mapping } \\
\text { and its products in comparison to your } \\
\text { professional colleagues? }\end{array}$ & $\begin{array}{l}\text { Much lesser understanding; Somewhat lesser } \\
\text { understanding; Same level of understanding; } \\
\text { Somewhat greater understanding; Much } \\
\text { greater understanding }\end{array}$ \\
\hline $\begin{array}{l}\text { Are you satisfied with the level of seismic } \\
\text { hazard mapping (mapped products) } \\
\text { available in Canada? }\end{array}$ & Yes or No \\
\hline $\begin{array}{l}\text { How informed or prepared do you think } \\
\text { you and your professional peers are for a } \\
\text { significant earthquake event in Canada? }\end{array}$ & $\begin{array}{l}\text { Not at all prepared (0) to Extremely prepared } \\
(10)\end{array}$ \\
\hline
\end{tabular}

Respondents evaluated their knowledge of seismic hazards and level of expertise with seismic hazard mapping in comparison to their professional colleagues (Table 3). Creators and technical users indicate high confidence in their knowledge (average rating of 7.9 and 7.3, respectively). Non-technical users evaluate their knowledge at an average rating of 5.7. On average, all respondent types rate their knowledge as same or somewhat greater than their professional peers.

Table 3: Respondent self-evaluations on seismic hazard knowledge and hazard mapping.

\begin{tabular}{|lccccccc|}
\hline Respondent type & $\begin{array}{c}\text { Self-declared } \\
\text { seismic hazard } \\
\text { knowledge }(0-10)\end{array}$ & $\begin{array}{c}\text { Understanding compared to peers (0-5) } \\
\text { (1) }\end{array}$ & $(2)$ & $(3)$ & $(4)$ & (5) & Average \\
\hline Creators & 7.9 & 1 & 0 & 6 & 11 & 5 & 3.8 \\
Users (Technical) & 7.3 & 0 & 0 & 1 & 4 & 1 & 4.0 \\
Users (Non-technical) & 5.7 & 2 & 0 & 9 & 6 & 1 & 3.2 \\
\hline
\end{tabular}


They were asked to indicate their satisfaction with the level of seismic hazard mapping available in Canada and their professions' degree of preparedness for a significant earthquake event in Canada (Table 4). Satisfaction with the level of seismic hazard mapping available in Canada is less than $50 \%$ for end-users; more significantly, $91 \%$ of creators are dissatisfied.

Table 4: Opinions on state of seismic hazard preparation in Canada.

\begin{tabular}{|lcc|}
\hline Respondent type & $\begin{array}{c}\text { Satisfaction with level of } \\
\text { hazard mapping } \\
\text { (percentage satisfied) }\end{array}$ & $\begin{array}{c}\text { How informed/prepared is your } \\
\text { profession for a significant } \\
\text { earthquake? (0-10) (average) }\end{array}$ \\
\hline Creators & 9 & 5.8 \\
Users (Technical) & 50 & 4.8 \\
Users (Non-technical) & 39 & 4.6 \\
\hline
\end{tabular}

\section{PRELIMINARY RECOMMENDATIONS AND DISCUSSION}

Feedback from the engagement workshop largely paralleled the recommendations of GasparEscribano and Iturrioz [1], and online survey responses begin to quantify stakeholders' seismic hazard competence. Recommendations can be grouped into three general themes.

\subsection{Graphical presentation}

Map design can improve comprehension, correct use and reception of seismic hazard products; therefore, map design must consider the specific needs of each potential user. Data may be represented by continuous or discrete spatial distribution. A continuous representation is appropriate for mapping relative hazard, for example regional scale seismic hazard (e.g. Canadian seismic hazard maps [30]). Discrete data representation is appropriate for mapping site-classification metrics. Choropleth mapping, using a colour scheme to shade units according to their value or class, is appropriate while the use of proportional symbols (discrete data points) to present data is not recommended. Workshop attendees indicated that discrete data points clutter the map as opposed to distinct coloured units. Additionally, users prefer no more than seven class intervals; three to five intervals are ideal.

Colour selection should be intuitive and hierarchically ordered. It is recommended that a single hue is selected (e.g. purple or orange), and lightness or grey value is uniformly adjusted for each class interval. The contrast of light and dark shades within a single hue is effective and minimizes misinterpretation. Colours provoking an emotional response (e.g. red, green and black) should be avoided wherever possible. This applies to the use of the green to red diverging colour ramp (e.g. Fig. 1(a) and (b)). This ramp is not accessible to colour-blind users and is often misinterpreted by all users. If a scale of increasing colour intensity is necessary, only areas of moderate to high hazard should be communicated; hazard colours (yellow for "moderate hazard" to red for "extreme hazard") are appropriate here. Intuitive gradation of neutral or colour-blind accessible hues is recommended.

\subsection{Hazard and site classification metrics}

Primary and intermediate users may require separate hazard map products due to different potential applications and degrees of seismic hazard knowledge, as identified from survey results. For primary users, data should be presented using the same parameters as the NBCC and other regulations for comparison purposes. Though workshop attendees comment that $\mathrm{V}_{\mathrm{S} 30}$ is not independently useful, in the current absence of another more appropriate metric, it is recommended to produce maps using the $\mathrm{V}_{\mathrm{S} 30}$ metric. Intermediate users (and the public) 
require hazard communicated in layman's terms (e.g. shaking intensity communicated like a "felt-report", or relative hazard) due to their low self-declared understanding of seismic hazard. Seismic hazard should be reclassified into categories of low to high hazard as the technical metrics and associated values are otherwise misunderstood and misinterpreted. Gaspar-Escribano and Iturrioz [1] also suggest that map legends differ for primary and intermediate users. Primary users require legends containing all information related to the represented metrics, whereas qualitative legends are preferred for intermediate users as they are sufficiently informative and comprehensible.

\subsection{Data format and accessibility}

Interactive map products are useful tools to address the needs of different users and cater to their cognitive profiles, stylistic preferences and desired applications [1]. It is widely requested to provide hazard data in the form of a mapping tool. This request is not surprising given advancements in computing; however, seismic hazard map products are typically not available in an interactive (digital) way in Canada. National-scale hazard maps are produced as static pdf or image files for download [30]. An interactive web tool [31] is used to request hazard values at a particular location (interpolated from nearby mapped points), but is primarily used by technical end-users (engineers). More widely recommended, and required by EMBC of the MVSMP, is to produce GIS shapefiles/layers. This format is more accessible as it can be manipulated and background data can be examined. Additionally, though proprietary datasets are not typically made publicly available, the nature of the hazard and potential impacts to society call for stakeholder access. A central repository or portal system should be established for relevant users to access data; it should be maintained and continually updated as new information becomes available.

\section{CONCLUSION}

A significant proportion of primary users are dissatisfied with seismic hazard mapping in Canada, and both primary and intermediate users believe their professions are only moderately prepared for a significant earthquake. This further supports the notion that updating seismic hazard information (e.g. the efforts of the MVSMP) is necessary to improve decision-makers' capacity to prepare for earthquake-related hazards. The initial stages of stakeholder consultation have highlighted the contrast between primary and intermediate users in terms of their fundamental hazard knowledge, metric comprehension and stylistic preferences for final map products. Investigation will continue; iterative consultation will play a vital role in determining the effective means to communicate detailed hazard information to intermediate users. The presented preliminary recommendations will be expanded as survey responses accumulate and will be applied to seismic microzonation map products in a move towards standardization. Rigorous scientific work might potentially go unused or misinterpreted if it is not properly communicated to the end-user. Improved map products, and therefore improved communication, increases overall hazard awareness and supports efforts to improve Vancouver's resilience to earthquakes.

\section{ACKNOWLEDGEMENTS}

Project funding provided by Emergency Management British Columbia through the Institute of Catastrophic Loss Reduction. Consultation with Dr. Stephanie Chang (University of British Columbia SCARP, Vancouver) greatly improved the design of our stakeholder engagement workshop. 


\section{REFERENCES}

[1] Gaspar-Escribano, J.M. \& Iturrioz, T., Communicating earthquake risk: Mapped parameters and cartographic representation. Nat. Hazards Earth Syst. Sci., 11(2), pp. 359-366, 2011. DOI: 10.5194/nhess-11-359-2011.

[2] Marti, M., Stauffacher, M. \& Wiemer, S., Difficulties in explaining complex issues with maps. Evaluating seismic hazard communication: The Swiss case. Nat. Hazards Earth Syst. Sci., pp. 1-32, 2019. DOI: 10.5194/nhess-2019-112.

[3] Taylor, G.W., Monahan, P., White, T.W. \& Ventura, C.E., British Columbia school seismic mitigation program: Dominant influence of soil type on life safety of Greater Vancouver and Lower Mainland schools of British Columbia. 8th US Natl. Conf. Earthq. Eng., 5, pp. 2490-2500, 2006.

[4] Cassidy, J.F., Rogers, G.C., Lamontagne, S., Halchuk, S. \& Adams, J., Canada's earthquakes: "The good, the bad, and the ugly". Geoscience Canada, 37(1), 2010.

[5] Office of the Auditor General of British Columbia, Auditor general report: Catastrophic earthquake preparedness, 2014. www.bcauditor.com/sites/default/files/ publications/2014/report_15/report/OAG\%20Catastrophic\%20Earthquake_FINAL. pdf. Accessed on: 22 Feb. 2020.

[6] SM Working Group, Editor guidelines for seismic microzonation. Conference of regions and autonomous Provinces of Italy, Civil Protection Department, Rome, 2015. www.protezionecivile.gov.it/httpdocs/cms/attach_extra/GuidelinesForSeismicMicroz onation.pdf. Accessed on: 22 Feb. 2020.

[7] Clague, J.J., The earthquake threat in southwestern British Columbia: A geologic perspective. Natural Hazards, 26(1), pp. 7-34, 2002.

DOI: 10.1023/A:1015208408485.

[8] Metro Vancouver Seismic Microzonation Project, https://metrovanmicromap.ca. Accessed on: 22 Feb. 2020.

[9] Molnar, S., Assaf, J., Sirohey, A. \& Adhikari, S.R., Overview of local site effects and seismic microzonation mapping in Metropolitan Vancouver, British Columbia, Canada. Engineering Geology, submitted for publication.

[10] Roger, G.C., Earthquakes and earthquake hazard in the Vancouver area. Geology and Natural Hazards of the Fraser River Delta, British Columbia, eds J.J. Clague, J.L. Luternauer \& D.C. Mosher, Geological Survey of Canada, Bulletin 525, pp. 17-25, 1998.

[11] Leonard, L.J., Currie, C.A., Mazzotti, S. \& Hyndman, R.D., Rupture area and displacement of past Cascadia great earthquakes from coastal coseismic subsidence. Bull. Geol. Soc. Am., 122(11-12), pp. 2079-2096, 2010. DOI: 10.1130/B30108.1.

[12] Jackson, F., Molnar, S., Ghofrani, H., Atkinson, G.M., Cassidy, J.F. \& Assatourians, K., Ground motions of the December 2015 M 4.7 Vancouver Island earthquake: Attenuation and site response. Bull. Seismol. Soc. Am., 107(6), pp. 2903-2916, 2017.

[13] Government of British Columbia, Seismic Mitigation Program, Capital Management Branch. Www2.gov.bc.ca/gov/content/education-training/k-12/administration/ capital/seismic-mitigation. Accessed on: 22 Feb. 2020.

[14] Government of British Columbia, Get prepared for an earthquake in British Columbia, PreparedBC. www2.gov.bc.ca/gov/content/safety/emergency-preparedness-responserecovery/preparedbc/know-your-hazards/earthquakes. Accessed on: 22 Feb. 2020.

[15] Hunter, J.A. \& Crow, H.L., Shear wave velocity measurement guidelines for Canadian seismic site characterization in soil and rock. Geol. Surv. of Canada, Open File 7078, p. 227, 2012. DOI: $10.4095 / 291753$. 
[16] Monahan, P.A., Levson, V.M., Henderson, P. \& Sy, A., Composite relative earthquake hazard map of Greater Victoria: Extended map legend, 2000. www.empr.gov.bc.ca/Mining/Geoscience/NaturalHazards/VictoriaEarthquakeMaps/ composite/Pages/default.aspx. Accessed on: 22 Feb. 2020.

[17] Socco, L.V. \& Strobbia, C., Surface-wave method for near-surface characterization: A tutorial. Near Surface Geophysics, 2, pp. 165-185, 2004.

[18] Building Seismic Safety Council, NEHRP recommended provisions for seismic regulations for new buildings. Part I: Provisions. Washington, DC, 1994. https://cdn.ymaws.com/www.nibs.org/resource/resmgr/BSSC/94NEHRP_Chapter1.p df. Accessed on: 22 Feb. 2020.

[19] National Research Council, NRCC National Building Code of Canada 2015, Associate Committee on the National Building Code, Ottawa, Ontario.

[20] Rosset, P., Bour-Belvaux, M. \& Chouinard, L., Microzonation models for Montreal with respect to VS30. Bull. Earthquake Eng., 13(8), pp. 2225-2239, 2015.

[21] Hunter, J.A. et al., Ottawa-Gatineau seismic site classification map from combined geological/geophysical data. Geol. Surv. of Canada, Open File 7067, 2012.

DOI: $10.4095 / 291440$.

[22] Leboeuf, D., Perret, D., Nollet, M.-J., Lamarche, L., Nastev, M. \& Parent, M., Microzonage sismique des villes de Québec: Ancienne-Lorette et réserve indienne Wendake (catégories d'emplacement), Québec. Geol. Surv. of Canada, Open File 6875, 2013. DOI: 10.4095/292640.

[23] Nastev, M., Parent, M., Benoit, N., Ross, M. \& Howlett, D., Regional VS30 model for the St. Lawrence lowlands, Eastern Canada. Georisk, 10(3), pp. 200-212, 2016.

[24] Journeay, J.M. et al., A profile of earthquake risk for the district of North Vancouver, British Columbia. Geol. Surv. of Canada, Open File 7677, p. 223, 2015.

[25] Rodriguez-Marek, A., Bray, J. \& Abrahamson, N.A., A geotechnical seismic site response evaluation procedure. Proceedings of 12th World Conference on Earthquake Engineering, Auckland, New Zealand, Paper Number 1590, 2000.

[26] Molnar, S. et al., Application of microtremor horizontal-to-vertical spectral ratio (MHVSR) analysis for site characterization: State of the art. Surveys in Geophysics, 39(4), pp. 613-631, 2018.

[27] Monahan, P.A. \& Levson, V.M., Development of a shear-wave velocity model of the near-surface deposits of southwestern British Columbia, Canada. Proceedings of the 4th International Conference on Recent Advances in Geotechnical Earthquake Engineering and Soil Dynamics, San Diego, California, Paper number 11.16, 2001.

[28] Monahan, P.A., Levson, V.M. \& Kerr, B., Liquefaction hazard map of Richmond, British Columbia. British Columbia Geological Survey, 2010. http://cmscontent.nrs.gov.bc.ca/geoscience/PublicationCatalogue/GeoscienceMap/ BCGS_GM2010-03.pdf. Accessed on: 22 Feb. 2020.

[29] Qualtrics XM, Metro Vancouver Seismic Microzonation Project online survey. https://uwo.eu.qualtrics.com/jfe/form/SV_cVoaJJV9d8jfrRr. Accessed on: 30 Mar. 2020.

[30] Earthquakes Canada, Natural Resources Canada, Earthquake Hazard. https://earthquakescanada.nrcan.gc.ca/hazard-alea/zoning-zonage/NBCC2015mapsen.php. Accessed on: 22 Feb. 2020.

[31] Earthquakes Canada, Natural Resources Canada, Seismic design tools for engineers. https://earthquakescanada.nrcan.gc.ca/hazard-alea/interpolat/index-en.php. Accessed on: 22 Feb. 2020. 